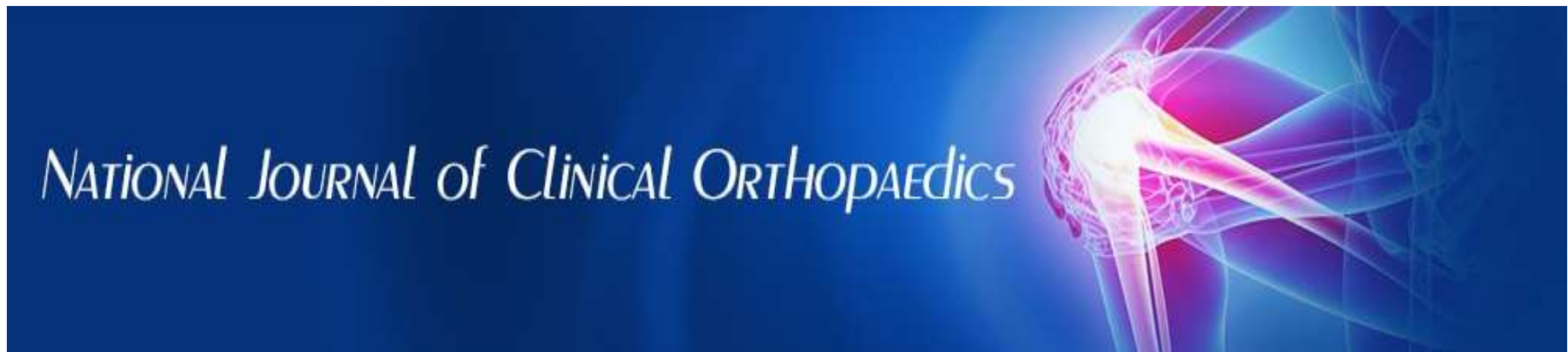

ISSN (P): 2521-3466

ISSN (E): 2521-3474

(C) Clinical Orthopaedics

www.orthoresearchjournal.com

2020; 4(3): $53-60$

Received: 26-05-2019

Accepted: 28-06-2019

Manjunath S Japatti

Department of Orthopaedics,

Lalith Orthopaedic Hospital

Sulepeth, Chincholi, Kalburgi,

Karnataka, India

Pavith T Janardhan

Senior Resident, Department of Orthopaedics, Kodagu Institute of Medical Sciences, Madikeri, Karnataka, India
Corresponding Author: Manjunath S Japatti Department of Orthopaedics, Lalith Orthopaedic Hospital Sulepeth, Chincholi, Kalburgi,

Karnataka, India

\section{A randomized control trial to compare the efficacy of intralesional platelet rich plasma vs steroid in lateral epicondylitis: A prospective interventional study}

\author{
Manjunath S Japatti and Pavith T Janardhan
}

DOI: https://doi.org/10.33545/orthor.2020.v4.i3a.302

\section{Abstract}

Background: lateral epicondylitis most commonly known as tennis elbow is not a rare entity. Most commonly seen in working population causing many work hour losses and thus leads to loss of income. Severity ranges from occasional pain to continuous dull aching leading to frustration and hindering the daily activities. It's a common practice to treat this condition with intralesional steroids. However, the recent developments in treatment advocates use of PRP in place of steroids. Hence, we conducted this study to compare and see the efficacy of both.

Methods: This is a prospective interventional study of 40 cases of lateral epicondylitis visited to our tertiary care private hospital during 2019 to 2020. Patients not amenable to analgesic were treated with intralesional steroid and PRP. 20 patients of each group received the treatment in double blinded randomised control fashion. Each patient assessed at regular interval for a period of 24 weeks and pain analysed with the help of VAS, FPS scoring and functional improvement with DASH score. Results were analysed with appropriate statistical method.

Results: In our study pre injection VAS score was comparable in both groups. The difference of pre injection VAS score was not much significant statistically. Both group of patients showed improvement in pain and functionality, reflected by decreasing VAS, FPS and DASH scores at 4 and 8 weeks. However, at 12- and 24-weeks improvement achieved with PRP was much better than the steroid. In the steroid group they cease to improv after 12 months and some patients even started experiencing pain again at 24 weeks. There is a significance difference between the two groups outcome seen at 24 weeks. Percentage of effect along with effect size achieved is also large in PRP group.

Conclusions: Both steroid and PRP are good for short term pain relief in management of lateral epicondylitis. However, in long term and sustained pain control PRP showed better outcome than steroid. Risk of recurrence is high with steroid than with the PRP.

Keywords: PRP, platelet rich plasma, tennis elbow, triamcinolone, VAS, FPS, DASH

\section{Introduction}

Lateral epicondylitis is the most common cause of non-traumatic elbow pain. It has a population prevalence of $1 \%-3 \%{ }^{[1]}$. In our community it is more common than the frequency stated in literatures. This is attributed to the strenuous working nature of Indian population. Specifically females working in the agricultural sector, lifting heavy weights and indulged in manual labouring. According to some study the peak incidence is seen in age group of 40-50 years with a slight female sex preponderance. Specially in females aged 42-46 years this incidence increases to $10 \%{ }^{[2,3]}$. These patients usually are engaged in activities that involve repetitive extension movements at the wrist ${ }^{[4-7]}$.

The presence of the condition can be dated back to $18^{\text {th }}$ century as documented by R.S Graham, a British surgeon. According to him the condition was first described by Runge in 1873. In 1882 Henry Morris referred this condition to as "Lawn Tennis arm" ${ }^{[8]}$. However, the term "Lawn-tennis elbow." was coined in $1883^{[9]}$.

Patient usually presents to specialist after a period of 1 to 2 months. During this time most of them were taking over the counter pain reliving medications such as NSAIDs, analgesic gel. However, it is not uncommon to see some patient with a history of osteopath and massage. These unscientific attempts usually don't relieve the pain and hinders the daily activity, forcing the frustrated patient to consult specialist. 
Many studies conducted in the past to describe the patho mechanism and to identify the structures involved in this condition. Repetitive microtrauma and microtear due to abnormally excess use of wrist extensors especially of extensor carpi radialis brevis (ECRB) with subsequent tendinosis and tear were identified as the main cause ${ }^{[10-13]}$. This leads to incomplete regeneration of injured common extensor tendons. It involves degenerative process caused by muscle overuse. Occurrence of this condition in athletes and nonathletes are alike ${ }^{[14]}$.

Non-operative treatments are aimed at decreasing repetitive use by rest and promoting regeneration of degenerated unhealthy pain-producing tendinosis tissue. Non operative treatment involves methods such as intralesional Corticosteroid injection ${ }^{[15]}$, Platelet rich plasma injection ${ }^{[16]}$, botulinum toxin injection ${ }^{[17]}$, Extracorporeal shock wave therapy ${ }^{[18]}$, and hyaluronic acid with chondroitin sulphate injection ${ }^{[19]}$. Although it has been described as a self-limiting condition, many patients do not show spontaneous resolution leading to a chronic condition [20, ${ }^{21]}$ surgical treatment is considered for those who fail to respond to conservative therapy ${ }^{[22]}$.

Platelets contain very powerful growth factors like plateletderived growth factor, transforming growth factor beta, and epidermal growth factor. The injection of PRP into the affected tissue initiates the healing stages necessary to reverse the degenerative process at the base of common extensor origin. The cytokines present in the alpha-granules have been shown to enhance fibroblast migration to the injured tissue and proliferation, promotes neo vascularisation and increase collagen deposition in a variety of in vitro and in vivo settings ${ }^{[23]}$.

Hence this double blind randomised controlled trial aims at comparing the efficacy of PRP and steroid for a period of 24 weeks post injection.

\section{Methods}

This is a double blind randomised clinical trial conducted at our private hospital. During period of January 2020 to July 2020. Study involves 40 patients, divided in to two groups of 20 each. All patients after excluding other possible causes of elbow pain diagnosed to have tennis elbow with positive Mill's and Cozens test. Such patients were subjected to ultrasonographic examination to confirm the diagnosis where it showed variable level of hypoechoic signals from the extensor tendons suggesting oedema. One group received intralesional triamcinolone acetonide and another group received PRP. Both groups were given post injection antibiotic amoxycillin clavulanate and paracetamol for five days. Improvement in pain and functional status of the patient analysed at regular intervals of 4 weeks, 8 weeks, 12 weeks and 24 weeks using VAS, FPS and DASH scoring. Final results were analysed using appropriate statistical tests.

PRP is prepared using differential spin technique. $15 \mathrm{ml}$ of patient's blood was drawn using scalp vein catheter. This blood is transferred equally to three tubes with $0.9 \%$ sodium citrate as anticoagulant. These three tubes were spinned for $15 \mathrm{~min}$ at 1500RPM. This separates the RBCs from rest of the blood components. Upper half of the supernatant fluid was discarded. Lower half of the supernatant fluid transferred to single tube. This single tube was subjected to second spin for $10 \mathrm{~min}$ at 2500RPM. Upper half of the supernatant was discarded. Remaining lower half of the supernatant was transferred to $1 \mathrm{ml}$ syringe containing $0.1 \mathrm{ml}$ of calcium chloride ${ }^{[24]}$ and part of it was sent for platelet count and compared with patients whole blood platelet count. This final $1 \mathrm{ml}$ of PRP was given to patients along with $1 \mathrm{ml}$ of $2 \%$ plain lignocaine under aseptic conditions. For another group also $1 \mathrm{ml}$ of triamcinolone was injected along with $1 \mathrm{ml}$ of $2 \%$ lignocaine.

\section{Results}

Our study includes 40 patients of lateral epicondylitis. Age ranges from 31 to 52 year. Majority of the patients were from age group of 31 to 41 year. Mean age of patient was 40.9 year. Both groups were comparable w.r.t age statistically. Study involves 25 Female (62.5\%) and 15 male (37.5\%) patients. Laterality wise right elbow was involved in 28 patients $(70 \%)$, left elbow was involved in remaining 12(30\%). Mean duration of presentation is 3.65 months. All demographic parameters were comparable in both steroid and PRP group.

Normality of data distribution for VAS, FPS and DASH score at different treatment times was determined by Kolmogorov Smirnov test. It was found that data followed normal distribution pattern. Hence data was analyzed with parametric studies. Dependent $\mathrm{t}$ tests were used for comparing the efficacy of steroid with PRP w.r.t VAS, FPS and DASH. Independent t test was applied to find out efficacy within group w.r.t mean VAS, FPS and DASH at various time period of test.

Table 1: Comparison of two drugs (Platelet rich plasma and steroid) with VAS scores at different treatment time points by independent test.

\begin{tabular}{|c|c|c|c|c|c|c|}
\hline \multirow{2}{*}{ Time points } & \multicolumn{2}{|c|}{ Platelet rich plasma } & \multicolumn{2}{|c|}{ Steroid } & \multirow{2}{*}{ t-value } & \multirow{2}{*}{ P-value } \\
\cline { 2 - 5 } & Mean & SD & Mean & SD & & \\
\hline Pre injection & 69.70 & 3.80 & 66.90 & 4.83 & 2.0370 & 0.0487 \\
\hline 4 weeks & 50.10 & 4.13 & 47.60 & 4.71 & 1.7860 & 0.0821 \\
\hline 8 weeks & 43.60 & 3.36 & 42.40 & 3.86 & 1.0487 & 0.3010 \\
\hline 12 weeks & 36.10 & 3.91 & 39.40 & 4.86 & -2.3670 & $0.0231^{*}$ \\
\hline 24 weeks & 31.40 & 3.49 & 40.10 & 6.50 & -5.2726 & $0.0001^{*}$ \\
\hline Pre Inj-4W & 19.60 & 6.07 & 19.30 & 4.85 & 0.1727 & 0.8638 \\
\hline Pre Inj-8W & 26.10 & 4.93 & 24.50 & 4.42 & 1.0808 & 0.2866 \\
\hline Pre Inj-12W & 33.60 & 5.33 & 27.50 & 6.17 & 3.3475 & $0.0018^{*}$ \\
\hline Pre Inj-24W & 38.30 & 4.68 & 26.80 & 8.05 & 5.5232 & $0.0001^{*}$ \\
\hline *p $<0.05$
\end{tabular}

Table 2: Comparison of different treatment time points with VAS scores in two drugs (Platelet rich plasma and steroid) by dependent $\mathrm{t}$ test

\begin{tabular}{|c|c|c|c|c|c|c|c|c|c|}
\hline Drugs & Time points & Mean & SD & Mean Diff. & SD Diff. & \% of effect & t-value & P-value & Effect size \\
\hline \multirow{4}{*}{ Platelet rich plasma } & Pre injection & 69.70 & 3.80 & & & & & & \\
\cline { 2 - 12 } & 4 weeks & 50.10 & 4.13 & 19.60 & 6.07 & 28.12 & 14.4328 & $<0.001$ & $\mathbf{0 . 8 3 2 0}$ \\
\cline { 2 - 11 } & Pre injection & 69.70 & 3.80 & & & & & & \\
\cline { 2 - 11 } & 8 weeks & 43.60 & 3.36 & 26.10 & 4.93 & 37.45 & 23.6758 & $<0.001$ & \\
\hline
\end{tabular}




\begin{tabular}{|c|c|c|c|c|c|c|c|c|c|}
\hline & Pre injection & 69.70 & 3.80 & & & & & & \\
\hline & 12 weeks & 36.10 & 3.91 & 33.60 & 5.33 & 48.21 & 28.2174 & $<0.001$ & \\
\hline & Pre injection & 69.70 & 3.80 & & & & & & \\
\hline & 24 weeks & 31.40 & 3.49 & 38.30 & 4.68 & 54.95 & 36.5965 & $<0.001$ & \\
\hline \multirow{8}{*}{ Steroid } & Pre injection & 66.90 & 4.83 & & & & & & \\
\hline & 4 weeks & 47.60 & 4.71 & 19.30 & 4.85 & 28.85 & 17.8108 & $<0.001$ & $\mathbf{0 . 7 7 3 0}$ \\
\hline & Pre injection & 66.90 & 4.83 & & & & & & \\
\hline & 8 weeks & 42.40 & 3.86 & 24.50 & 4.42 & 36.62 & 24.7954 & $<0.001$ & \\
\hline & Pre injection & 66.90 & 4.83 & & & & & & \\
\hline & 12 weeks & 39.40 & 4.86 & 27.50 & 6.17 & 41.11 & 19.9368 & $<0.001$ & \\
\hline & Pre injection & 66.90 & 4.83 & & & & & & \\
\hline & 24 weeks & 40.10 & 6.50 & 26.80 & 8.05 & 40.06 & 14.8889 & $<0.001$ & \\
\hline
\end{tabular}

$* \mathrm{p}<0.05$

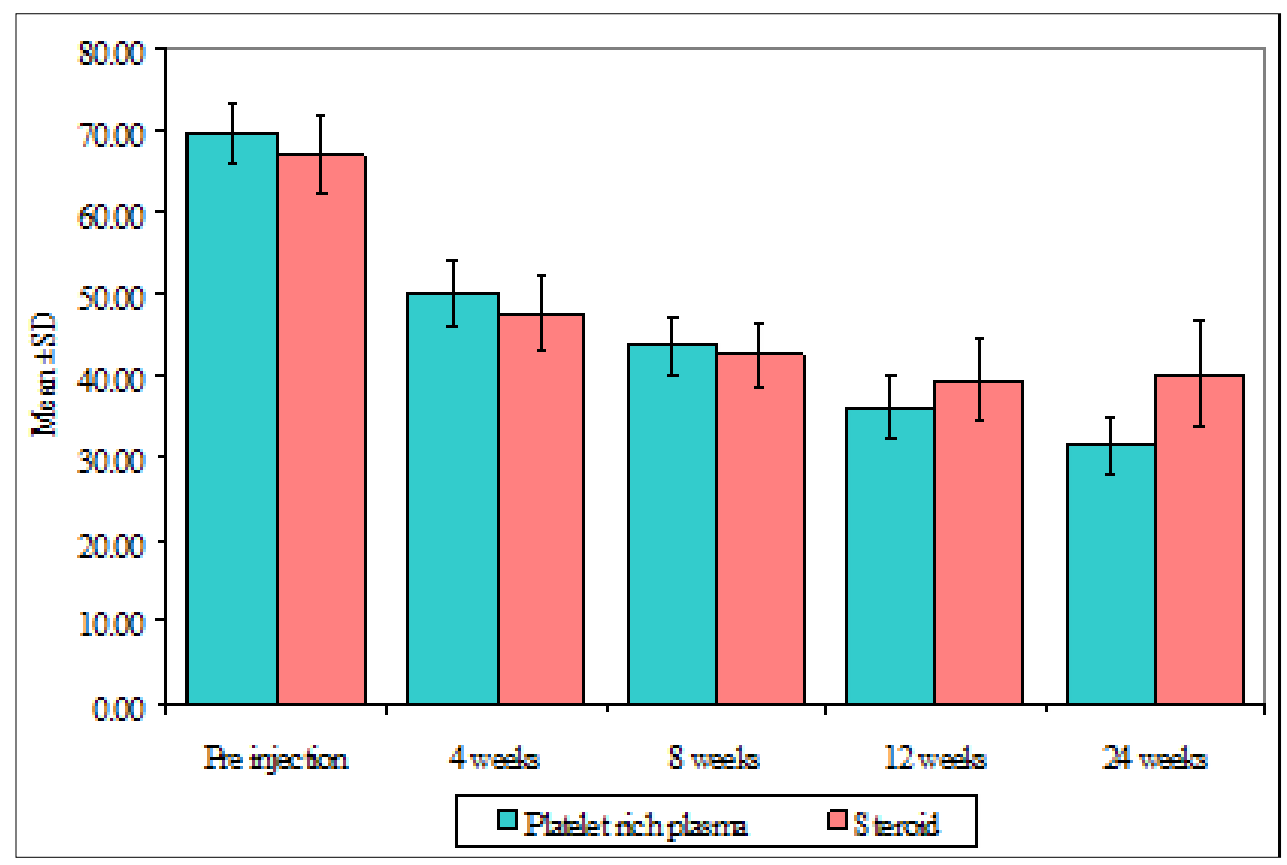

Fig 1: Comparison of two drugs with VAS scores at different treatment time points

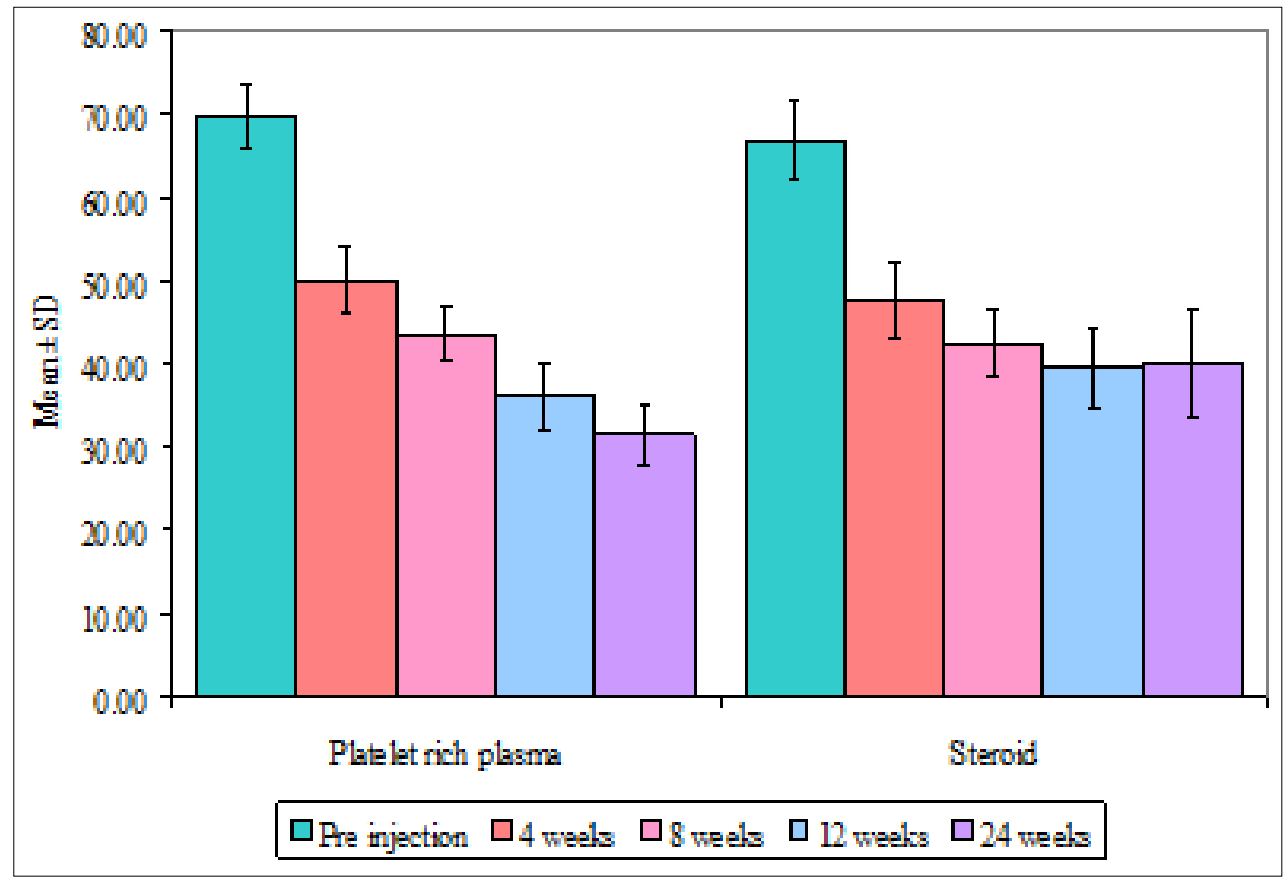

Fig 2: Comparison of different treatment time points with VAS scores in two drugs 
Table 4: Comparison of different treatment time points with FPS scores in two drugs (Platelet rich plasma and steroid) by dependent $t$ test

\begin{tabular}{|c|c|c|c|c|c|c|}
\hline \multirow{2}{*}{ Time points } & \multicolumn{2}{|c|}{ Platelet rich plasma } & \multicolumn{2}{|c|}{ Steroid } & \multirow{2}{*}{ t-value } & \multirow{2}{*}{ P-value } \\
\cline { 2 - 6 } & Mean & SD & Mean & SD & & 0.2281 \\
\hline Pre injection & 71.15 & 8.55 & 68.15 & 6.84 & 1.2250 & 0.2435 \\
\hline 4 weeks & 53.30 & 5.65 & 50.95 & 6.84 & 1.1847 & 0.3110 \\
\hline 8 weeks & 46.30 & 6.37 & 44.40 & 5.29 & 1.0268 & $0.0128^{*}$ \\
\hline 12 weeks & 36.40 & 6.21 & 41.25 & 5.51 & -2.6116 & $0.0001^{*}$ \\
\hline 24 weeks & 27.65 & 4.16 & 42.75 & 9.65 & -6.4259 & 0.7440 \\
\hline Pre Inj-4W & 17.85 & 7.27 & 17.20 & 5.02 & 0.3289 & 0.5263 \\
\hline Pre Inj-8W & 24.85 & 6.08 & 23.75 & 4.71 & 0.6395 & $0.0033^{*}$ \\
\hline Pre Inj-12W & 34.75 & 8.72 & 26.90 & 7.00 & 3.1396 & $0.0001^{*}$ \\
\hline Pre Inj-24W & 43.50 & 7.44 & 25.40 & 11.79 & 5.8070 & \\
\end{tabular}

Table 3: Comparison of two drugs (Platelet rich plasma and steroid) with FPS scores at different treatment time points by independent test

\begin{tabular}{|c|c|c|c|c|c|c|c|c|c|}
\hline Drugs & Time points & Mean & SD & Mean Diff. & SD Diff. & $\%$ Of effect & t-value & P-value & Effect size \\
\hline \multirow{8}{*}{ Platelet rich plasma } & Pre injection & 71.15 & 8.55 & & & & & & \\
\hline & 4 weeks & 53.30 & 5.65 & 17.85 & 7.27 & 25.09 & 10.9785 & $<0.001$ & 0.9840 \\
\hline & Pre injection & 71.15 & 8.55 & & & & & & \\
\hline & 8 weeks & 46.30 & 6.37 & 24.85 & 6.08 & 34.93 & 18.2759 & $<0.001$ & \\
\hline & Pre injection & 71.15 & 8.55 & & & & & & \\
\hline & 12 weeks & 36.40 & 6.21 & 34.75 & 8.72 & 48.84 & 17.8156 & $<0.001$ & \\
\hline & Pre injection & 71.15 & 8.55 & & & & & & \\
\hline & 24 weeks & 27.65 & 4.16 & 43.50 & 7.44 & 61.14 & 26.1565 & $<0.001$ & \\
\hline \multirow{8}{*}{ Steroid } & Pre injection & 68.15 & 6.84 & & & & & & \\
\hline & 4 weeks & 50.95 & 6.84 & 17.20 & 5.02 & 25.24 & 15.3166 & $<0.001$ & 0.7800 \\
\hline & Pre injection & 68.15 & 6.84 & & & & & & \\
\hline & 8 weeks & 44.40 & 5.29 & 23.75 & 4.71 & 34.85 & 22.5438 & $<0.001$ & \\
\hline & Pre injection & 68.15 & 6.84 & & & & & & \\
\hline & 12 weeks & 41.25 & 5.51 & 26.90 & 7.00 & 39.47 & 17.1969 & $<0.001$ & \\
\hline & Pre injection & 68.15 & 6.84 & & & & & & \\
\hline & 24 weeks & 42.75 & 9.65 & 25.40 & 11.79 & 37.27 & 9.6351 & $<0.001$ & \\
\hline
\end{tabular}

$* \mathrm{p}<0.05$

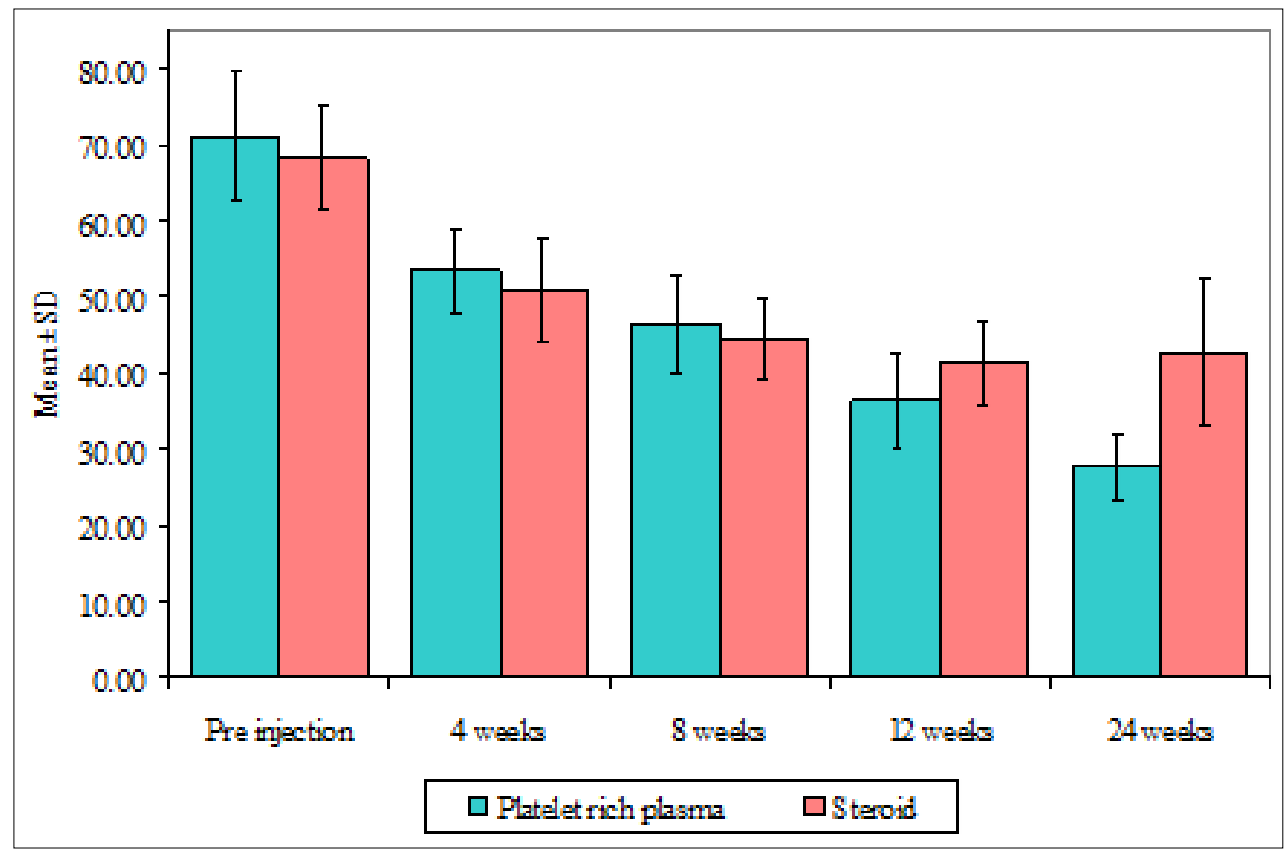

Fig 3: Comparison of two drugs with FPS scores points with FPS scores in two drugs 


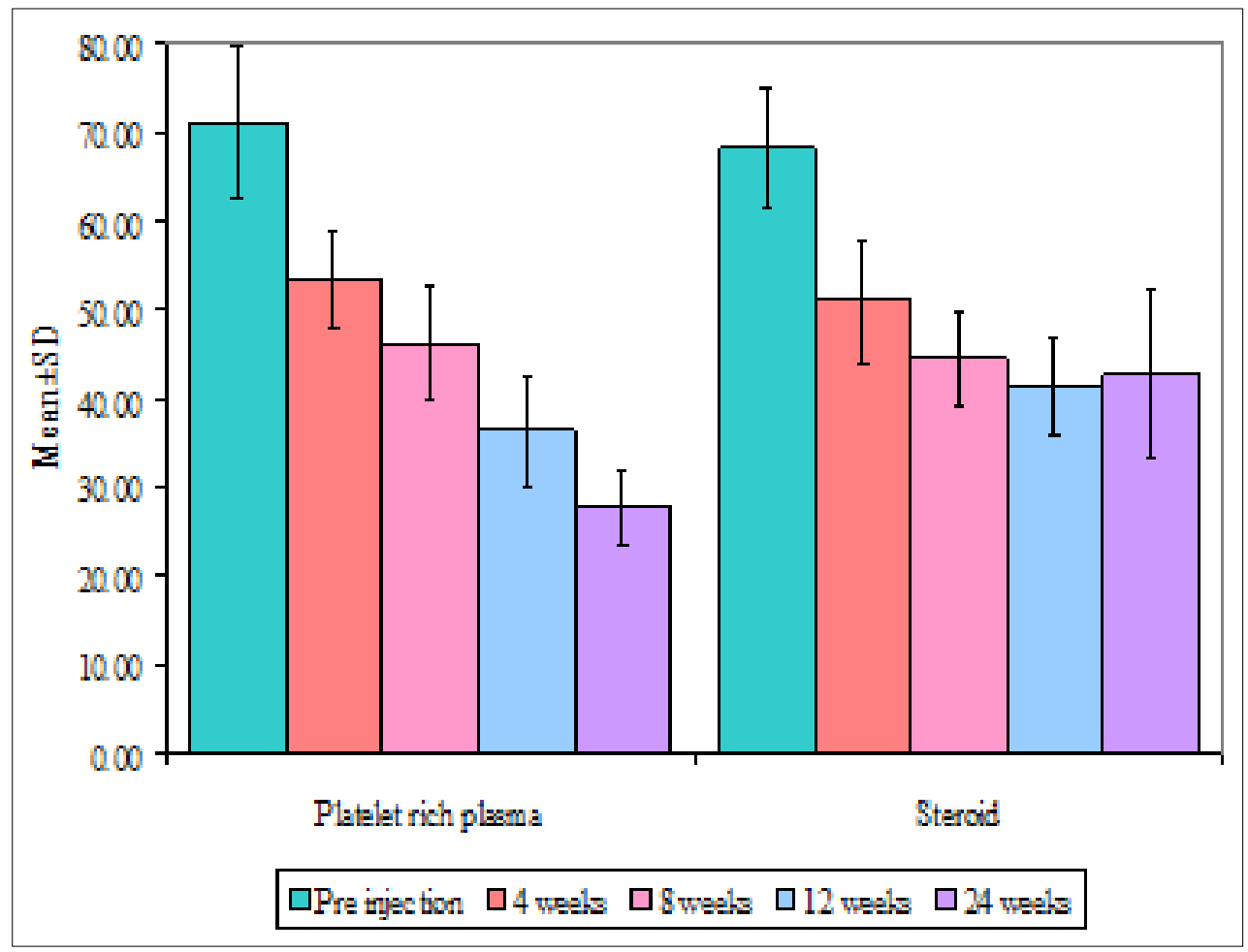

Fig 4: Comparison of different treatment time at different treatment time points

Table 5: Comparison of two drugs (Platelet rich plasma and steroid) with DASH scores at different treatment time points by independent $t$ test

\begin{tabular}{|c|c|c|c|c|c|c|}
\hline \multirow{2}{*}{ Time points } & \multicolumn{2}{|c|}{ Platelet rich plasma } & \multicolumn{2}{c|}{ Steroid } & \multirow{2}{*}{ t-value } & \multirow{2}{*}{ P-value } \\
\cline { 2 - 5 } & Mean & SD & Mean & SD & & \\
\hline Pre injection & 58.55 & 6.02 & 56.30 & 5.85 & 1.1986 & 0.2381 \\
\hline 4 weeks & 43.50 & 4.25 & 42.00 & 6.39 & 0.8741 & 0.3875 \\
\hline 8 weeks & 36.55 & 5.27 & 35.80 & 3.99 & 0.5074 & 0.6148 \\
\hline 12 weeks & 32.40 & 3.07 & 34.20 & 3.68 & -1.6804 & 0.1011 \\
\hline 24 weeks & 30.40 & 1.43 & 34.25 & 4.72 & -3.4896 & $0.0012^{*}$ \\
\hline Pre Inj-4W & 15.05 & 8.03 & 14.30 & 4.74 & 0.3598 & 0.7210 \\
\hline Pre Inj-8W & 22.00 & 7.70 & 20.50 & 3.66 & 0.7868 & 0.4363 \\
\hline Pre Inj-12W & 26.15 & 5.90 & 22.10 & 5.83 & 2.1843 & $0.0352^{*}$ \\
\hline Pre Inj-24W & 28.15 & 5.42 & 22.05 & 7.05 & 3.0667 & $0.0040^{*}$ \\
\hline
\end{tabular}
$* \mathrm{p}<0.05$

Table 6: Comparison of different treatment time points with DASH scores in two drugs (Platelet rich plasma and steroid) by dependent $t$ test

\begin{tabular}{|c|c|c|c|c|c|c|c|c|c|}
\hline Drugs & Time points & Mean & SD & Mean Diff. & SD Diff. & \% of effect & t-value & P-value & Effect size \\
\hline \multirow{8}{*}{ Platelet rich plasma } & Pre injection & 58.55 & 6.02 & & & & & & \\
\hline & 4 weeks & 43.50 & 4.25 & 15.05 & 8.03 & 25.70 & 8.3824 & $<0.001$ & 0.9860 \\
\hline & Pre injection & 58.55 & 6.02 & & & & & & \\
\hline & 8 weeks & 36.55 & 5.27 & 22.00 & 7.70 & 37.57 & 12.7804 & $<0.001$ & \\
\hline & Pre injection & 58.55 & 6.02 & & & & & & \\
\hline & 12 weeks & 32.40 & 3.07 & 26.15 & 5.90 & 44.66 & 19.8340 & $<0.001$ & \\
\hline & Pre injection & 58.55 & 6.02 & & & & & & \\
\hline & 24 weeks & 30.40 & 1.43 & 28.15 & 5.42 & 48.08 & 23.2188 & $<0.001$ & \\
\hline \multirow{8}{*}{ Steroid } & Pre injection & 56.30 & 5.85 & & & & & & \\
\hline & 4 weeks & 42.00 & 6.39 & 14.30 & 4.74 & 25.40 & 13.5027 & $<0.001$ & 0.7710 \\
\hline & Pre injection & 56.30 & 5.85 & & & & & & \\
\hline & 8 weeks & 35.80 & 3.99 & 20.50 & 3.66 & 36.41 & 25.0251 & $<0.001$ & \\
\hline & Pre injection & 56.30 & 5.85 & & & & & & \\
\hline & 12 weeks & 34.20 & 3.68 & 22.10 & 5.83 & 39.25 & 16.9526 & $<0.001$ & \\
\hline & Pre injection & 56.30 & 5.85 & & & & & & \\
\hline & 24 weeks & 34.25 & 4.72 & 22.05 & 7.05 & 39.17 & 13.9829 & $<0.001$ & \\
\hline
\end{tabular}




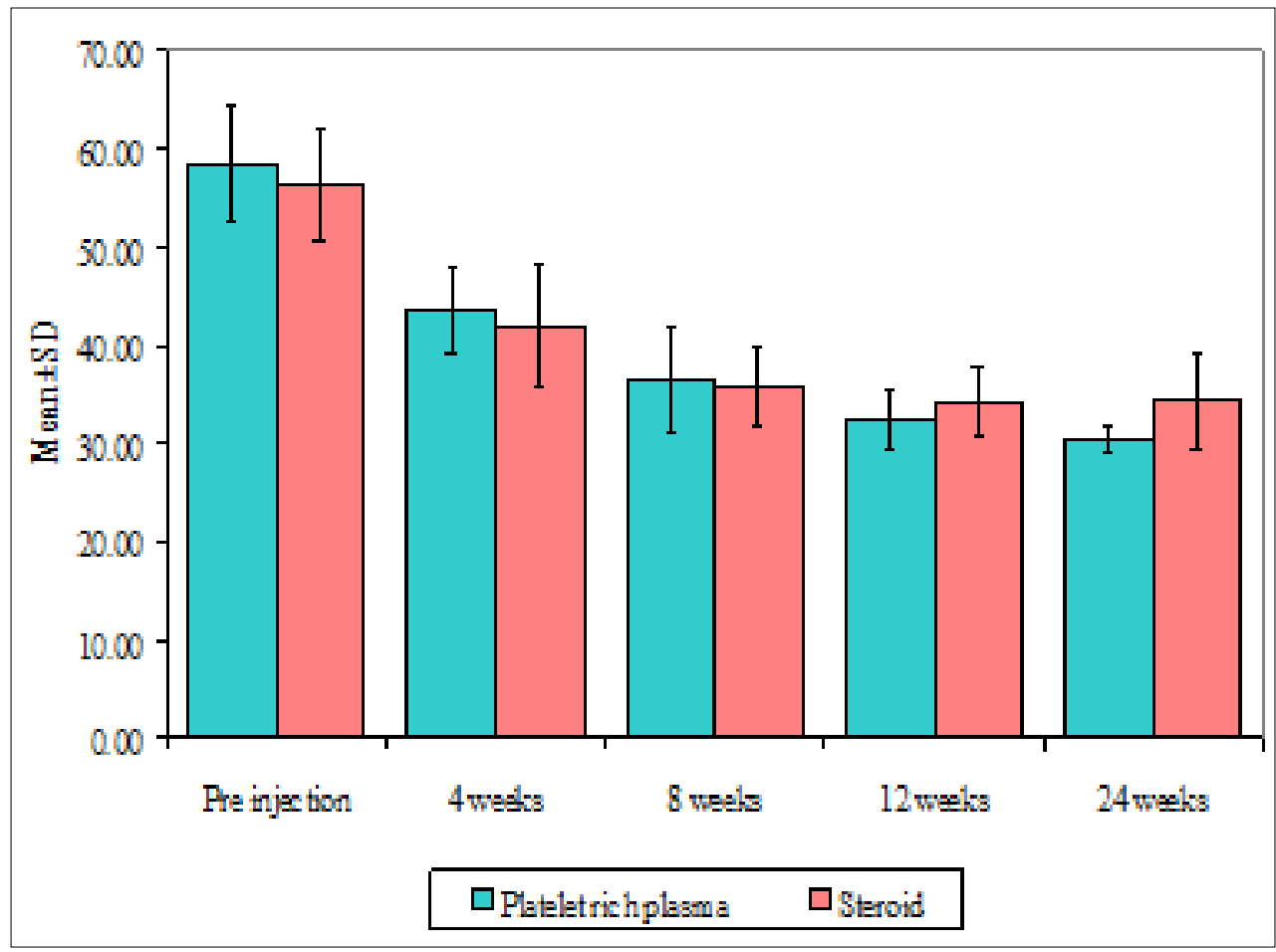

Fig 5: Comparison of two drugs with DASH scores at different treatment time points

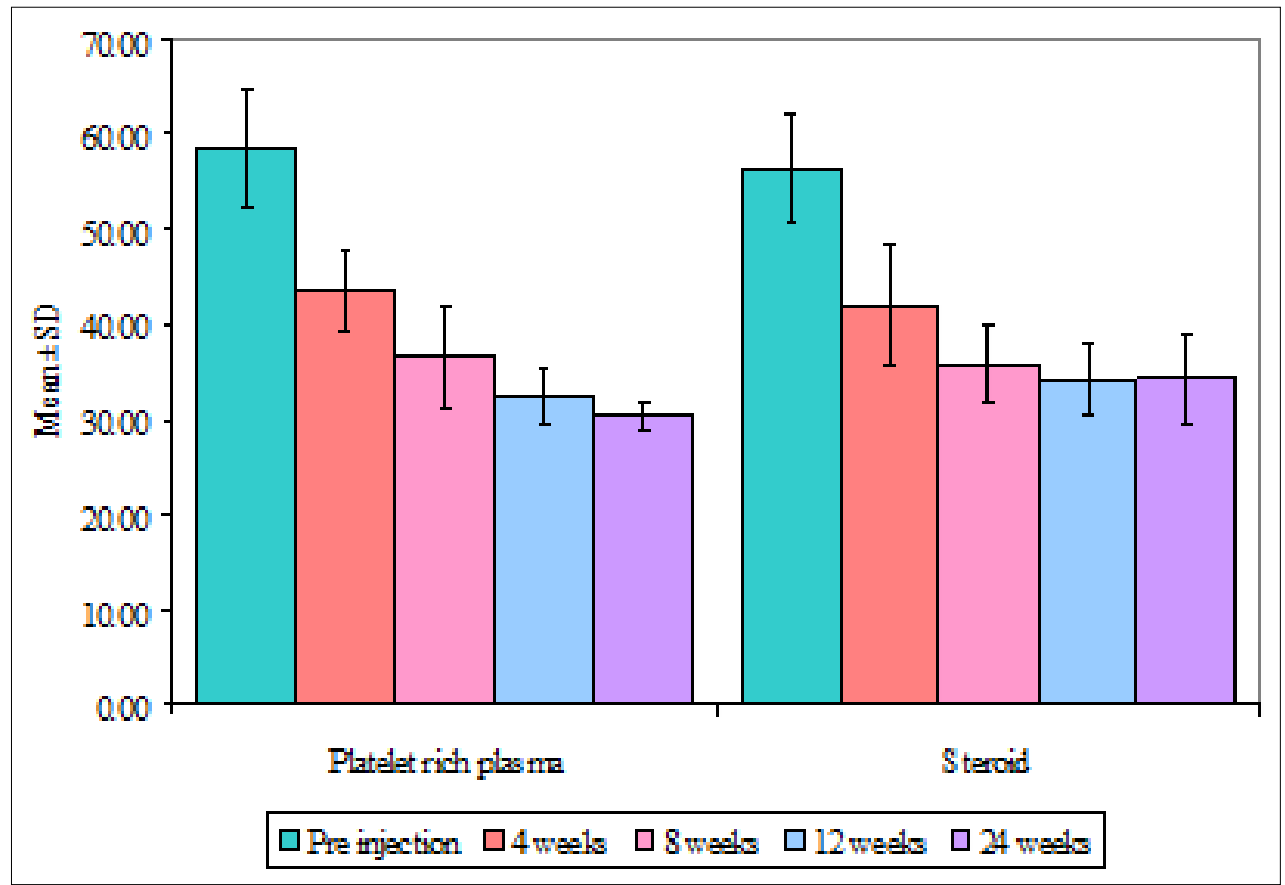

Fig 6: Comparison of different treatment time points with Dash scores in two drugs 


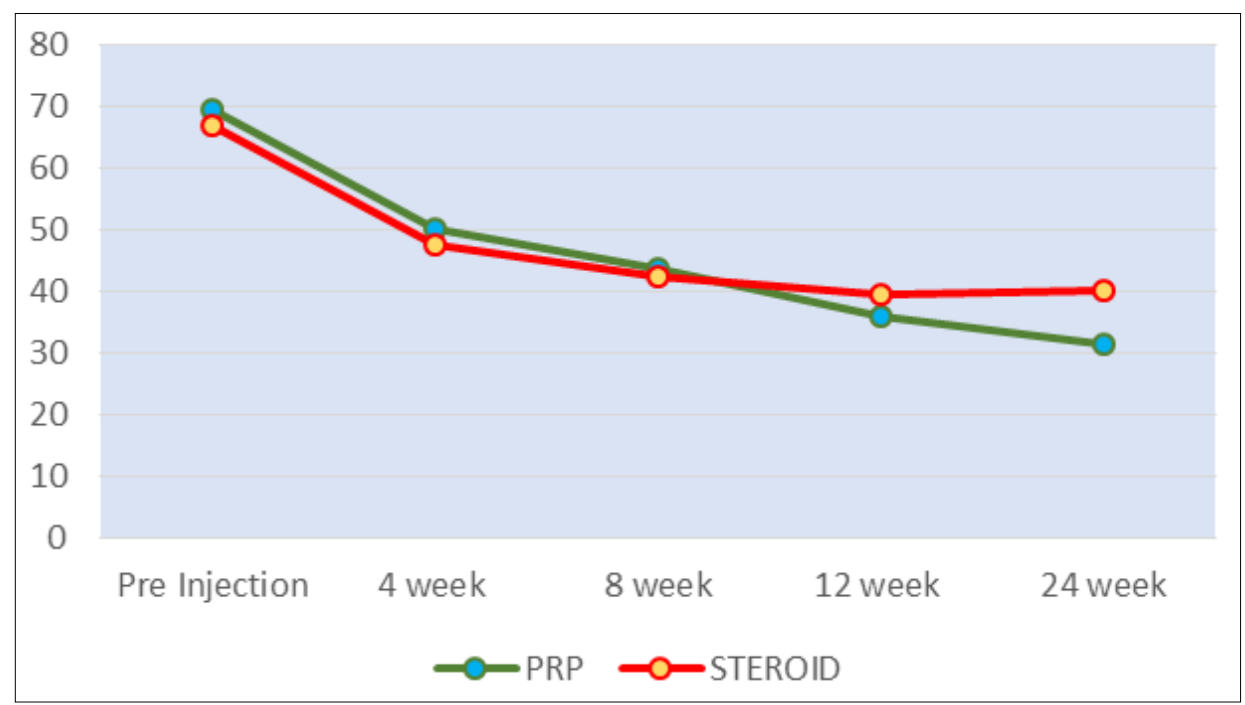

Fig 7: Line diagram depicting trend in VAS score with both treatment

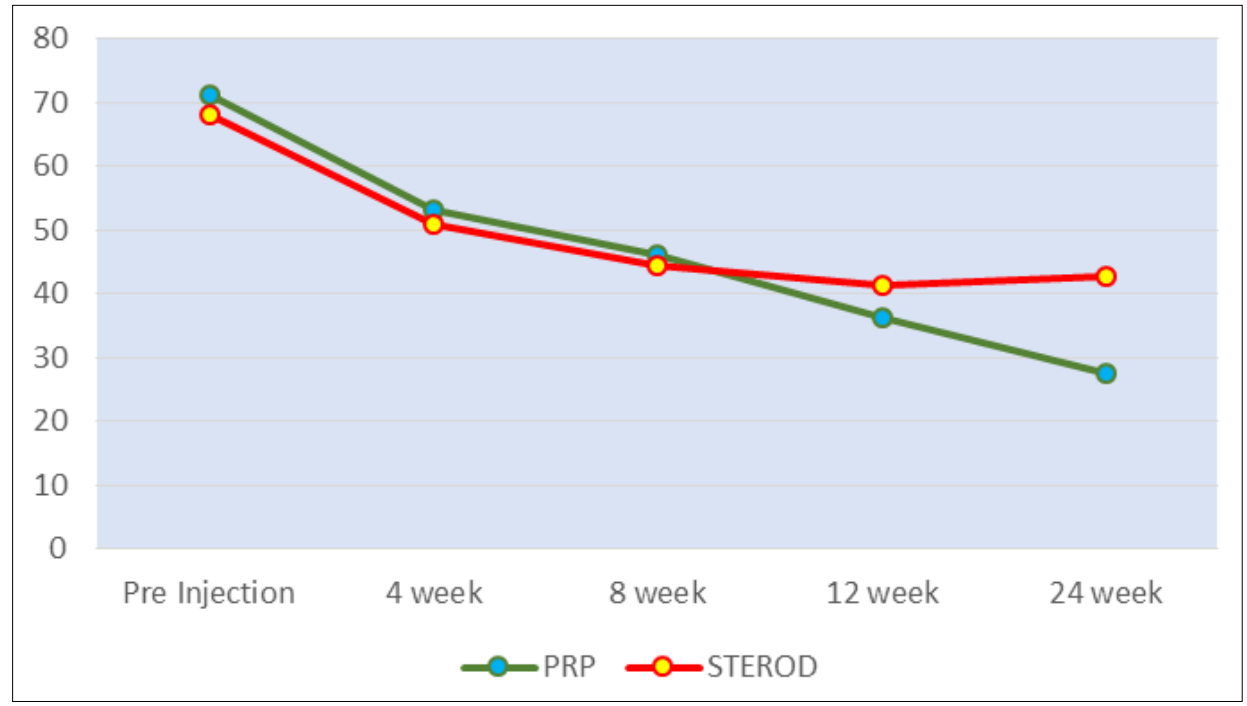

Fig 8: Line diagram depicting trend in FPS score with both treatment

\section{Discussion}

In our community Lateral epicondylitis is a more common problem than stated in literature. Its continuous dull aching pain not only causes loss of many work hours but also cripples the patient's ability to do the daily house hold activities. Most of the affected population belongs to manual labours. Before presenting to us many of them had a course of over-the-counter analgesics and osteopath massage. This further adds to the problem which demands next level of care. It is a common practice to give intralesional steroid injections for lateral epicondylitis not relieved with analgesics after a treatment for a period of 2 months. Recurrence of pain is a major issue seen in many studies with steroids. However recent advances advocates use of PRP for long term relief. Hence this study was conducted to assess the efficacy of PRP over steroids.

In our study the pre injection VAS score was comparable statistically in both groups. The difference was not much significant. Both group of patients showed improvement in pain and functionality, reflected by decreasing VAS, FPS and DASH scores at 4 and 8 weeks. However, at 12- and 24-weeks improvement achieved with PRP was much better than steroid. In the steroid group they stopped improving and some patients even started experiencing pain again at 24 weeks. There is a significance difference between the two group's outcomes seen at 24 weeks. Percentage of effect along with effect size achieved is also large in PRP group.

Many studies favour the PRP over steroids. A study by

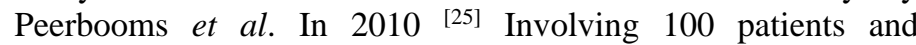
demonstrated a positive effect of PRP for tennis elbow. This report describes the first comparison of an autologous PRP with corticosteroid injection as a treatment for tennis elbow. Study states that these improvements seen with PRP were sustained over time with no reported complications. In another study patients with chronic lateral epicondylitis who took platelet-rich plasma not only experienced reduced pain but also had significant functional improvement, exceeding the effect of corticosteroid injection even after a follow-up of 2 years ${ }^{[26]}$. In another study, it was found that intralesional platelet-rich plasma injection showed significant pain relief and gain in function as well as quality of life 6 months after intervention [27, 28, 29].

However, some studies failed to prove superiority of PRP over steroids. The study conducted by shiple BJ et al. Didn't find any adequate pain relief with a single injection of platelet-rich plasma, after 3 months of short followup ${ }^{[30]}$. Many other studies showed inconclusive results ${ }^{[31-33]}$. Poor pain relief on long term in case of steroid was due to its limited capacity to aid in healing of tendinosis as compared to PRP.PRP is rich in many granules and growth factors which aid in rapid healing and thus long-term 
pain control ${ }^{[34]}$. No complications were noticed in our study.

Limitation of the study; Small sample size and short duration.

\section{Conclusion}

Both steroid and PRP are good for short term pain relief in management of lateral epicondylitis. However, in long term and sustained pain control PRP showed better outcome than steroid. Risk of recurrence is high with steroid than with the PRP.

\section{Declarations}

Funding: None

Conflict of interest: None

Ethical approval: This study was approved by institutional ethical committee.

\section{References}

1. Allander E. Prevalence, incidence, and remission rates of some common rheumatic diseases or syndromes. Scand J Rheumatol 1974;3:145-53.

2. Chard MD, Hazleman BL. Tennis elbow - A reappraisal. Br J Rheumatol 1989;28:186-90.

1. Verhaar JA. Tennis elbow. Anatomical, epidemiological and therapeutic aspects. Int Orthop 1994;18:263-7.

3. Childress MA, Beutler A. Management of chronic tendon injuries. Am Fam Physician 2013; 1(87):486-490.

4. Gruchow HW, Pelletier D. An epidemiologic study of tennis elbow: incidence, recurrence, and effectiveness of prevention strategies. Am J Sports Med 1979;7(4):234-8.

5. Geoffroy P, Yaffe MJ, Rohan I. Diagnosing and treating lateral epicondylitis. Can Fam Physician 1994;40:73-8.

6. Chard MD, Hazleman BL. Tennis elbow - A reappraisal. Br J Rheumatol 1989;28:186-90.

7. Thurston AJ. The early history of tennis elbow: to the1950s. ANZ Journal of Surgery 1873;68(3):219-224.

8. Major HP. Lawn tennis elbow BMJ 1883;2:557.

9. Walz DM, Newman JS, Konin GP, Ross G. Epicondylitis: Pathogenesis, imaging, and treatment. Radiographic 2010;30:167-84.

10. Fredberg U, Stengaard-Pedersen K. Chronic tendinopathy tissue pathology, pain mechanisms, and etiology with a special focus on inflammation. Scand J Med Sci Sports 2008;18(1):3-15.

11. Regan W, Wold LE, Coonrad R, Morrey BF. Microscopic histopathology of chronic refractory lateral epicondylitis. Am J Sports Med 1992;20(6):746-9.

12. Shiri R, Vikari-Juntura E. Lateral and medial epicondylitis: role of occupational factors. Best Pr Res Clin Rheumatol 2011;25(1):43-57.

13. Brummel J, Baker CL 3rd, Hopkins R, Baker CL Jr. Epicondylitis: Lateral. Sports Med Arthrosc 2014;22:e1-6.

14. Saccomanni B. Corticosteroid injection for tennis elbow or lateral epicondylitis: A review of the literature. Curr Rev Musculoskeletal Med 2010;3:38-40.

15. Edwards SG, Calandruccio JH. Autologous blood injections for refractory lateral epicondylitis. J Hand Surg Am 2003;28:272-8.

16. Galvin R, Callaghan C, Chan WS, Dimitrov BD, Fahey T. Injection of botulinum toxin for treatment of chronic lateral epicondylitis: Systematic review and meta-analysis. Semin Arthritis Rheum 2011;40:585-7.

17. Chung B, Wiley JP. Effectiveness of extracorporeal shock wave therapy in the treatment of previously untreated lateral epicondylitis: A randomized controlled trial. Am J Sports Med 2004;32:1660-7.
18. Tosun HB, Gumustas S, Agir I, Uludag A, Serbest S, Pepele $\mathrm{D}$, et al. Comparison of the effects of sodium hyaluronate chondroitin sulphate and corticosteroid in the treatment of lateral epicondylitis: A prospective randomized trial. J Orthop Sci 2015;20:837-43.

19. Verhaar JA. Tennis elbow. Anatomical, epidemiological and therapeutic aspects. Int Orthop 1994;18:263-7.

20. Mishra A, Woodall J, Vieira A. Treatment of tendon and muscle using platelet-rich plasma. Clin Sports Med. 2009;28:113-125.

21. Walz DM, Newman JS, Konin GP, Ross G. Epicondylitis: Pathogenesis, imaging, and treatment. Radiographics 2010;30:167-84.

22. Molloy T, Wang Y, Murrell G. The roles of growth factors in tendon and ligament healing. Sports Med 2003;33:38194.

23. Carola Cavallo, Alice Roffi, Brunella Grigolo, et al., "Platelet-Rich Plasma: The Choice of Activation Method Affects the Release of Bioactive Molecules," BioMed Research International 2016, 7. Article ID 6591717, [NCBI]

24. Peerbooms J, et al. Positive effect of an autologous platelet concentrate in lateral epicondylitis in a double blind randomised controlled trial: PRP versus corticosteroid injection with a 1-year follow-up. Am J Sports Med 2010;38:255-62.

25. Gosens T, Peerbooms JC, van Laar W, den Oudsten BL. Ongoing positive effect of platelet rich plasma versus corticosteroid injection in lateral epicondylitis: A doubleblind randomized controlled trial with 2-year follow-up. Am J Sports Med 2011;39:1200-08.

26. Brkljac M, Kumar S, Kalloo D, Hirehal K. The effect of platelet-rich plasma injection on lateral epicondylitis following failed conservative management. J Orthop 2015;12:S166-70.

27. Varshney A, Maheshwari R, Juyal A, Agrawal A, Hayer P. Autologous platelet-rich plasma versus corticosteroid in the management of elbow epicondylitis: A randomized study. Int J Appl Basic Med Res 2017;7:125-28.

28. Brkljac M, Kumar S, Kalloo D, Hirehal K. The effect of platelet-rich plasma injection on lateral epicondylitis following failed conservative management. J Orthop 2015;12:S166-70.

29. Shiple BJ. How effective are injection treatments for lateral epicondylitis? Clin J Sport Med 2013;23:502-03.

30. Raeissadat SA, Rayegani SM, Hassanabadi H, Rahimi R, Sedighipour L, Rostami K. Is platelet rich plasma superior to whole blood in the management of chronic tennis elbow? One year randomized clinical trial. BMC Sports Sci Med Rehabil 2014;6:12.

31. Mishra A, Pavelko T. Treatment of chronic elbow tendinosis with buffered platelet-rich plasma. Am J Sports Med 2006;34:1774-78.

32. Mishra A, Collado H, Fredericson M. Platelet-rich plasma compared with corticosteroid injection for chronic lateral elbow tendinosis. PMR 2009;1:366-70.

33. Tonks JH, Pai SK, Murali SR. Steroid injection therapy is the best conservative treatment for lateral epicondylitis: A prospective randomised controlled trial. Int $\mathrm{J}$ Clin Pract 2007;61:240-46. 